\title{
Maximum power injection acceptance in a residential area
}

\author{
C. Debruyne ${ }^{1,2}$, J. Desmet $^{1,2}$, J. Vanalme ${ }^{1,2}$, B. Verhelst ${ }^{1,2}$, G. Vanalme ${ }^{1,2}$, L. Vandevelde ${ }^{2}$ \\ ${ }^{1}$ HOWEST, Department GKG \\ Graaf Karel de Goedelaan 5, B-8500 Kortrijk (Belgium) \\ Phone:+ 32562412 35, e-mail: colin.debruyne@howest.be, jan.desmet@howest.be, johan.vanalme@howest.be, \\ bart.verhelst@howest.be, greet.vanalme@ howest.be \\ ${ }^{2}$ Ghent University, Department EESA \\ Sint-Pietersnieuwstraat 41, B-9000 Ghent (Belgium) \\ Phone: +32 926434 22, e-mail: lieven.vandevelde@ugent.be
}

\begin{abstract}
The number of installed distributed generation (DG) in residential areas rapidly increases, specifically in the form of photovoltaics (PV), causing some undesired side effects such as voltage rise. Overvoltage can damage critical loads, but is also disadvantageous for the owner because inverters switch off in case of overvoltage, resulting in output loss. Voltage limits are investigated through calculation and simulation of the voltage profile in a typical low voltage (LV) grid by using load data. Insolation data is used for the particular case of PV. This paper presents practical guidelines for the maximum power acceptance in a residential distribution network and the estimation of PV production loss due to overvoltage.
\end{abstract}

\section{Key words}

distributed generation, simulation, hosting capacity, photovoltaic power, overvoltage

\section{Introduction}

In recent years the number of photovoltaic (PV) installations in residential areas is increasing rapidly due to environmental awareness, increasing energy prices and incentives from the government. Distributed generation (DG) causes some challenges for the distribution network operator such as reverse power flow, increased shortcircuit power, unintentional islanding, selectivity of protections, stability problems and power quality issues like harmonic distortion and voltage rise [1]-[2]. Overvoltage can damage critical loads, but also the PV owner can suffer because inverters switch off in case of overvoltage, resulting in PV production loss.

Unlike the efforts of the Belgian national and local government for the fast and massive implementation of renewable energy sources in general, there are little regulatory measures for connecting distributed generation with a rated power of less than $10 \mathrm{~kW} \mathrm{[3].} \mathrm{This} \mathrm{has} \mathrm{led} \mathrm{to}$ a situation where the responsible grid operator no longer has an accurate overview of the number, location and amount of DG. The problems are dominant for residential grids.
This paper gives a guideline for the determination of the maximum power that may be injected in a distribution network without violating voltage limits, by using equivalent power injection calculations. Moreover the paper gives a guideline to choose the peak power of a PV installation that will be placed in an existing network, taking into account the location in the network, load and $\mathrm{PV}$ production profiles as well as PV production losses due to overvoltage. Simulations and calculations are performed for a Belgian residential area.

\section{Residential area}

For the simulations a hypothetical but representative Belgian residential area is used. The Belgian network contains two specific types of residential LV grids, namely the compact urban grid and the rural grid. The rural grids are more sensitive to the discussed problem since these grids are older, the connection points are more dispersed and the amount of installed power is usually higher.

The European voltage norm EN50160 states that the 10 minute average RMS voltage at the point of common coupling (PCC) must lay within the $\pm 10 \% U_{\text {nom }}$ limits for $95 \%$ of the time, with $U_{\text {nom }}=230 \mathrm{~V}_{\text {RMS }}$. [4] In order to maintain the voltage at the end of the feeder inside these boundaries the transformer secondary voltage is set at $241 \mathrm{~V}_{\mathrm{RMS}}$.

The generalised network consists of a $630 \mathrm{kVA}$ transformer and feeders EAXVB $4 \times 150 \mathrm{~mm}^{2}$ with maximum length of $975 \mathrm{~m}$. Houses are equally divided over the three phases. The distance between the houses is $25 \mathrm{~m}$. Simulations confirm that the influence of the grid impedance, varying from $180 \mathrm{MVA}$ to $500 \mathrm{MVA}$, and of the transformer impedance is marginal in relation to the feeder impedance. 


\section{Equivalent power injection}

\section{A. Influence of point of injection on voltage profile}

Figure 1 shows the voltage profile along a feeder with 1 power injection $(10 \mathrm{~kW})$ and no load as a function of the injection location.

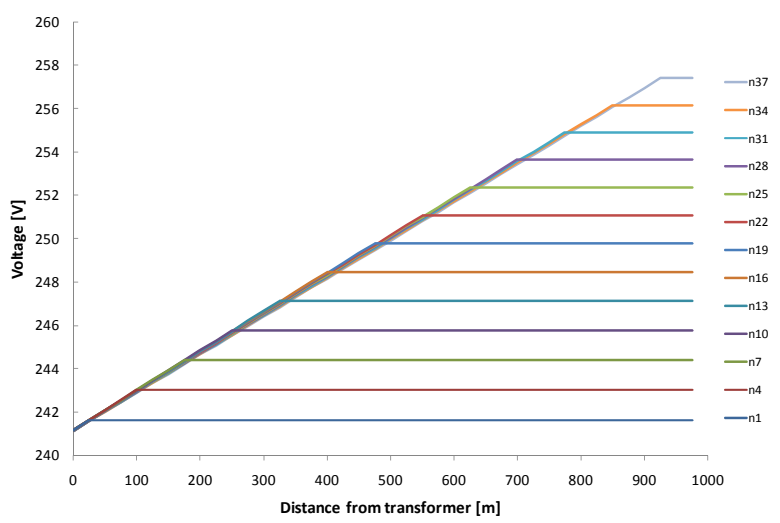

Fig. 1. Influence of point of injection on voltage profile

It can be seen that the voltage at the point of injection rises when the distance between injection point and transformer increases. The relationship is not exactly linear because for constant power injections, currents are smaller at higher voltages. However, voltages calculated with a constant current approximation deviate only slightly from the simulated values $(0.5 \%$ deviation for the voltage at the end of the feeder).

In a three phase system there will also be a voltage drop in the neutral conductor. Due to the shifting of the neutral voltage at PCC, all three phase-neutral voltages will shift. Dependent on the voltage phase and the $\mathrm{L} / \mathrm{R}$ ratio of the feeder, the other voltages will shift and result in a higher or lower phase voltage. Simulation results verify that the voltage rise on the injected phase is the limiting factor for the maximum power acceptance.

For a single phase injection and equal sections of phase and neutral conductors, the voltage at the injection point is given by:

$$
U_{I P}=U_{s}+2 . Z \frac{P}{U_{I P}} l
$$

where $U_{I P}$ and $U_{s}$ are the voltages [V] at injection point and transformer respectively, $Z$ the cable impedance $[\Omega / \mathrm{m}], P$ the injected power $[\mathrm{W}]$ and $l[\mathrm{~m}]$ the distance between injection point and transformer.

\section{B. Maximum power injection as a function of distance}

Voltage-distance curves can be set up for different values of power injection. Alternatively, for a given maximum voltage $U_{\max }$, the maximum power injection at a certain distance can be determined by:

$$
P . l=\frac{\left(U_{\max }-U_{s}\right) \cdot U_{\max }}{2 . Z}
$$

Figure 2 shows approximate calculation results obtained by using (3) and values from table I. Equation (3) is derived by using the voltage drop expression from the standard NF C15-100 (4) and by assuming a constant current.

$$
\begin{gathered}
P . l=\operatorname{Constant}\left(U_{\max }, Z\right) \\
\Delta U=b .\left(\rho \frac{L}{S} \cos \varphi+\lambda . L \cdot \sin \varphi\right) . I
\end{gathered}
$$

where $\Delta U$ is the cable voltage drop, $b$ a constant ( 1 or 2 , for three and single phase circuits respectively), $\rho$ the resistivity and $\lambda$ the reactance of the conductors, $L$ the length and $S$ the section of the cable, $I$ the current and $\varphi$ the phase shift between current and voltage.

The figure also presents simulation results for $U_{\max }=\mathrm{U}_{110 \%,} U_{\max }=\mathrm{U}_{108 \%}$, and $U_{\max }=\mathrm{U}_{106 \%}$, which is respectively $110 \%, 108 \%$ and $106 \%$ of the nominal voltage of $230 \mathrm{~V}_{\mathrm{RMS}}$ according to the EN50160 standard.

Deviations between calculated and simulated values are small for higher distances. For locations near the transformer the calculated maximum power injection is less than the simulated value. This is due to the simplified scalar approach, instead of the correct vectorial computation. In general it can be concluded that the calculated power can be injected without violating the voltage limit.

Table I. - Electric momentum for different allowed voltages

\begin{tabular}{|c|c|}
\hline $\begin{array}{c}\text { ALLOWED } \\
\text { VOLTAGE }\end{array}$ & $\begin{array}{c}\text { ELECTRIC } \\
\text { MOMENTUM }\end{array}$ \\
\hline$U_{\max }=U_{110 \%}=253,0 \mathrm{~V}$ & $P . l=6690 \mathrm{kWm}$ \\
\hline$U_{\max }=U_{108 \%}=248,4 \mathrm{~V}$ & $P . l=4056 \mathrm{kWm}$ \\
\hline$U_{\max }=U_{106 \%}=243,8 \mathrm{~V}$ & $P . l=1506 \mathrm{kWm}$ \\
\hline
\end{tabular}

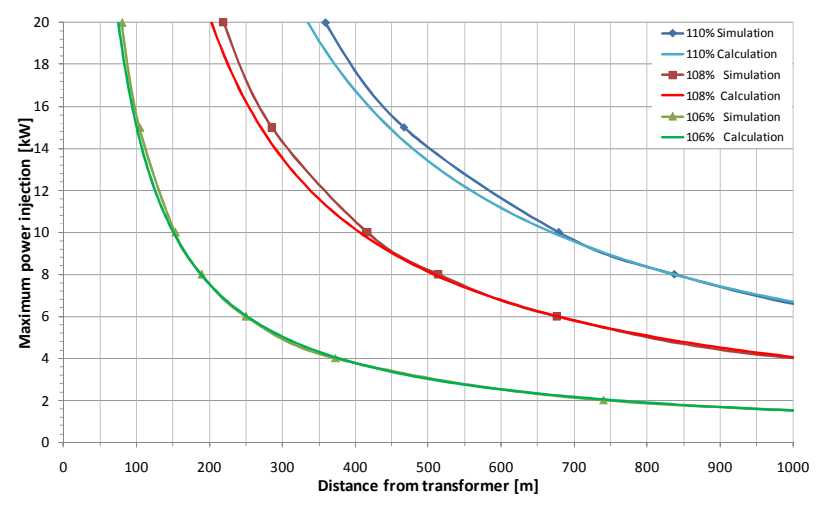

Fig. 2. Maximum power injection as a function of distance for different allowed voltages: simulations and calculations 


\section{Equivalent power injection}

Equation (3) means that the electric momentum is constant for a given grid and maximum voltage. By this electric momentum a certain injected power at a certain distance can be converted to an equivalent power injection at a specific distance.

This way all power injections along a feeder can be converted to a single equivalent power injection at the end of the feeder (5).

$$
P_{e}=\frac{\sum P_{i} \cdot l_{i}}{L}
$$

where $P_{e}$ is the equivalent power injection, $i$ the location index, $P_{i}$ the power injection at location $i, l_{i}$ the distance between location $i$ and the transformer, $L$ the total feeder length.

The equivalent power injection approach can be generically used for all kinds of situations (e.g. other cable sections, different sections between phase and neutral conductors, three phase injections). Table II gives some electric momentum values for other configurations.

Table II. - Electric momentum for different configurations

\begin{tabular}{|l|l|l|}
\hline CABLE TYPE & $\begin{array}{l}\text { POWER } \\
\text { INJECTION }\end{array}$ & $\begin{array}{l}\text { ELECTRIC } \\
\text { MOMENTUM } \\
\text { FOR } U_{\max }=253 \mathrm{~V} \\
\text { (per injected phase) }\end{array}$ \\
\hline EAXVB 4x150 & Single phase & $P_{e} \cdot L=6690 \mathrm{kWm}$ \\
\hline BXB 3x95+54 & Single phase & $P_{e} \cdot L=2700 \mathrm{kWm}$ \\
\hline EAXVB 4x150 & Three phase & $P_{e} \cdot L=7725 \mathrm{kWm}$ \\
\hline BXB 3x95+54 & Three phase & $P_{e} \cdot L=4272 \mathrm{kWm}$ \\
\hline
\end{tabular}

\section{PV production losses}

\section{A. Time dependent profiles}

The previous reasoning is valid for all kinds of DG. In following the specific situation for PV production is simulated.

The power consumption distribution is obtained from the Flemish market regulator VREG [5]. The power consumption is given on a 15 minute basis, but is recalculated to a 10 minute basis for the simulations.

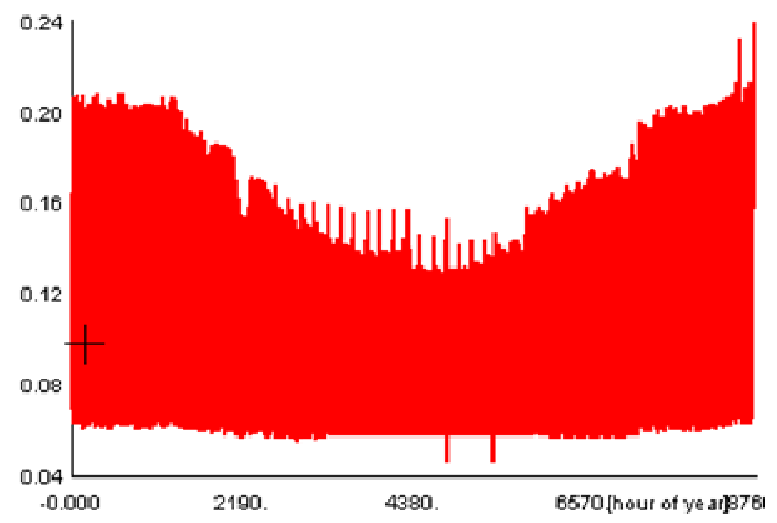

Fig. 3. Residential power consumption during a year, normalized to 1000 p.u. for the yearly total [5].

In this paper the assumption is made that the PV production is proportional to the energy density from the sunlight. A standard sunlight year is used for the energy density distribution [7].

The production from a Flemish PV installation of $1 \mathrm{kWp}$ is, according to a general rule of thumb, set equal to a $850 \mathrm{kWh}$ on annual basis. From the energy density on a half hour basis, a PV production is derived on a 10 minute basis.

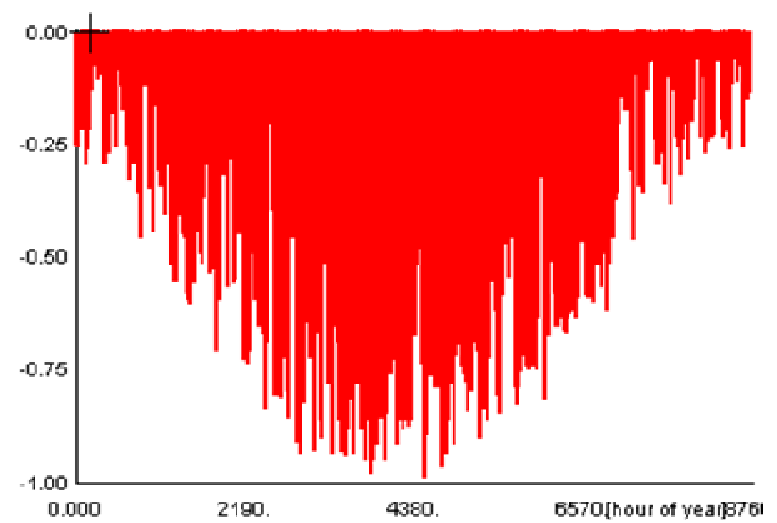

Fig. 4. PV production in a Belgian area during a year, normalized to 1 p.u. peak [7].

In order to simulate the network voltages over one year along the feeder, the time dependent load and PV production profiles (fig.3, fig.4) are combined. Since consumption and production data were recalculated to 10 minute values, the results are 10 minute average voltages in accordance with EN50160. In this situation the assumption is made that inverters will not switch off due to overvoltage. As a result 210240 voltage values are calculated $(8760 \mathrm{~h} / \mathrm{y} * 6$ times $10 \mathrm{~min} / \mathrm{h})$. 


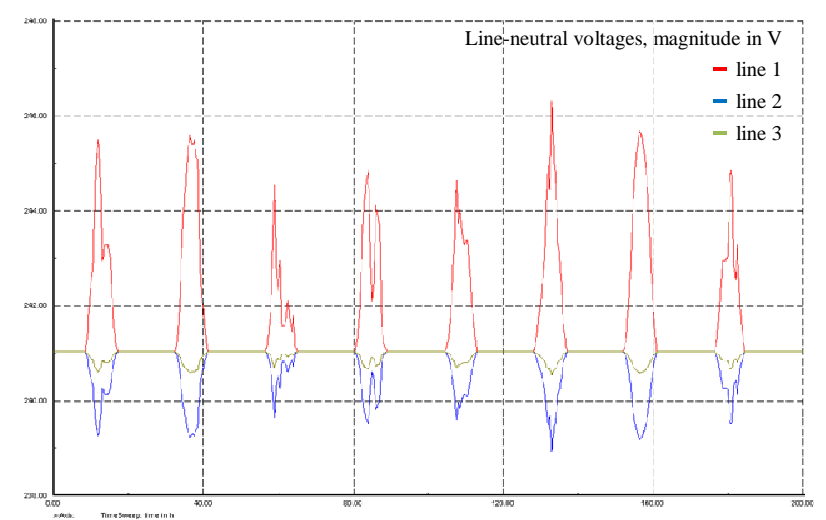

(a) no load

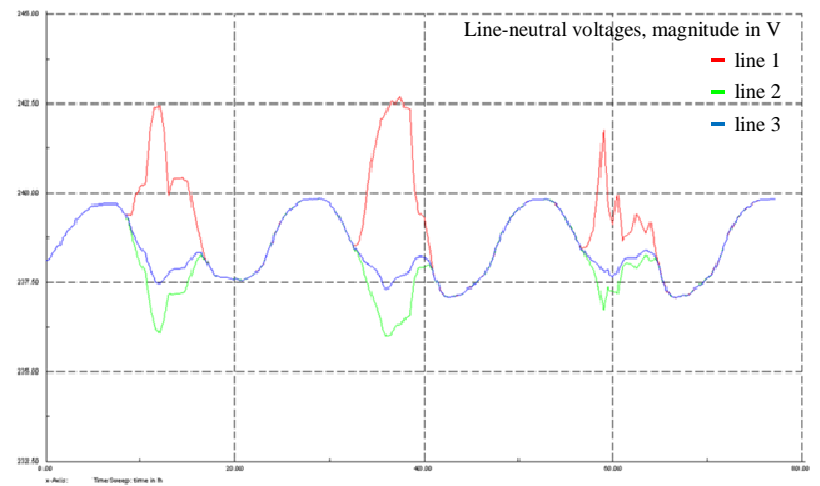

(b) all phases loaded by $12 \times 3 \mathrm{~kW}_{\mathrm{p}}$ profiles

Fig. 5. Voltage variation at the end of the feeder when $10 \mathrm{kWp}$ $\mathrm{PV}$ is installed at the end of the feeder on phase A.

\section{B. Probability of voltage limit exceeding}

The 210240 computed samples are used to determine the probability function of the voltage. Figure 6 shows the yearly percentage the stated voltage limit is exceeded for different PV peak power and the cases with and without load.

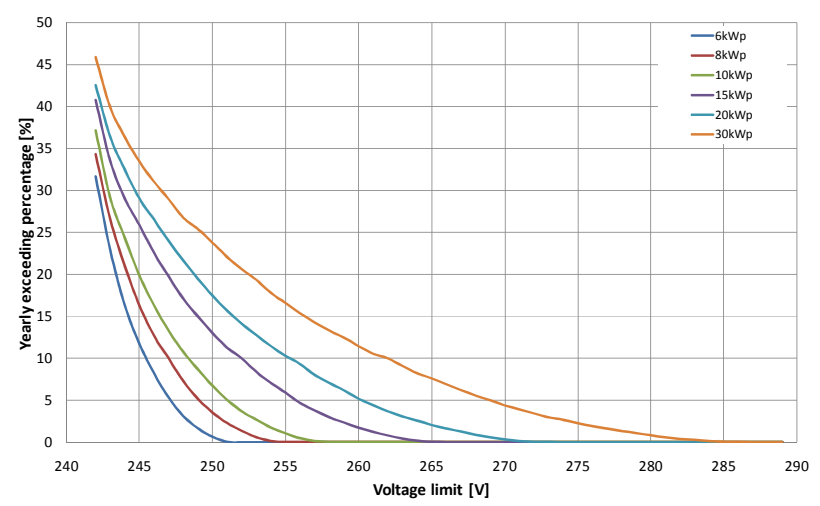

(a) no load

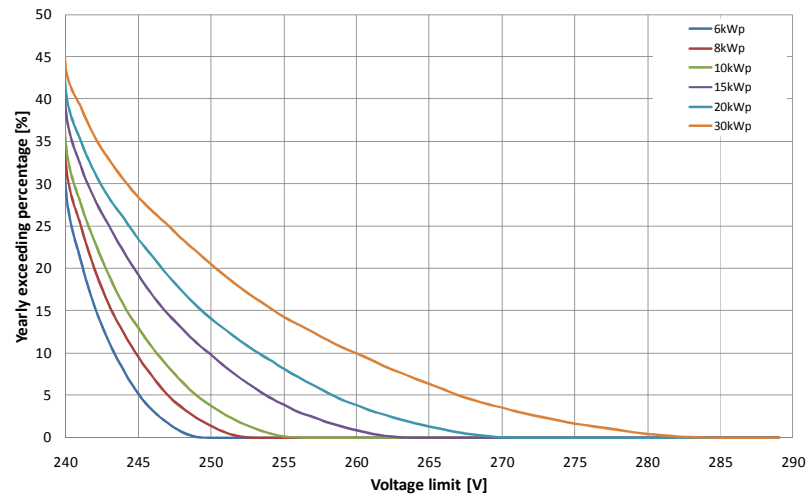

(b) all phases loaded by $12 \times 3 \mathrm{~kW}_{\mathrm{p}}$ profiles

Fig. 6. Yearly percentage of voltage limit exceeding for different PV peak power

From these results, the yearly percentage of overvoltage (voltage $>253 \mathrm{~V}_{\mathrm{RMS}}$ ) can be plotted against the installed PV peak power (fig.7).

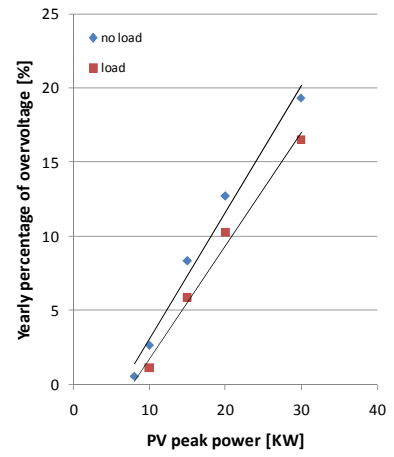

(a) linear

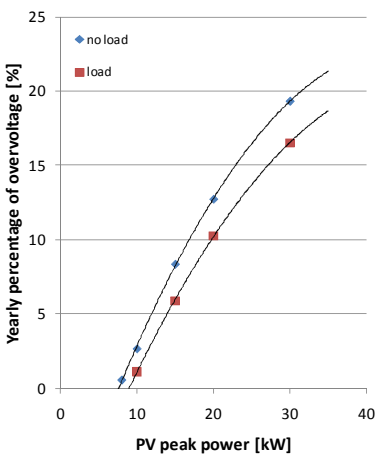

(b) quadratic
Fig. 7. Yearly percentage of overvoltage vs. PV peak power in case of no load and all phases loaded by $12 \times 3 \mathrm{~kW}_{\mathrm{p}}$ profiles

The percentage of overvoltage for an arbitrary loading (0$100 \%$ of houses is consuming power) lies between minimum and maximum values, which can be linearly approximated by (6) and (7) respectively:

$$
\begin{aligned}
& Y_{>253 V, \text { min }}=0.76 x-5.87 \\
& Y_{>253 V, \text { max }}=0.86 x-5.49
\end{aligned}
$$

where $Y_{>253 \mathrm{~V} \text {, min }}$ and $Y_{>253 \mathrm{~V} \text {, max }}$ are the minimum and maximum values of the yearly overvoltage percentage respectively, and $x=P_{P V \text {,peak }}[\mathrm{kW}]$ the installed PV peak power at the end of the feeder.

It is clear that the situation without load is the worst-case scenario, giving maximum values.

A more accurate estimate is obtained by second order expansions, which take into account the saturating effect for higher power amounts:

$$
\begin{aligned}
& Y_{>253 V, \text { min }}=-0.0169 x^{2}+1.499 x-10.45 \\
& Y_{>253 V, \text { max }}=-0.0139 x^{2}+1.328 x-10.83
\end{aligned}
$$


In case the real PV injection is not at the end of the feeder, expression (5) can be used to calculate the equivalent injection.

\section{PV production losses}

In case of overvoltage, inverters must switch off in accordance with the Belgian $\mathrm{C} 10-11$ regulations [3]. The switching will result in voltage oscillations and production losses. From the simulation results the yearly production loss in $\mathrm{kWh}$ can be evaluated (table III, fig. 8). Similarly minimum and maximum values are found for the load and no load cases respectively (fig. 9, table IV).

Table III. - Yearly production and loss due to overvoltage vs. $\mathrm{PV}$ peak power in case of single phase injection at the end of the feeder and all phases loaded by $12 \times 3 \mathrm{kWp}$ profiles

\begin{tabular}{|r|c|c|c|c|c|c|l|}
\hline INSTALLED & 6 & 8 & 10 & 15 & 20 & 30 & $\mathrm{kWp}$ \\
\hline TOTAL & 5100 & 6800 & 8500 & 12750 & 17000 & 25500 & $\mathrm{kWh} / \mathrm{y}$ \\
\hline LOSS & 0 & 2,08 & 692,2 & 4371 & 8837 & 17926 & $\mathrm{kWh} / \mathrm{y}$ \\
\hline$\%$ LOSS & 0 & 0,03 & 8,14 & 34,28 & 51,98 & 70,30 & $\%$ \\
\hline
\end{tabular}

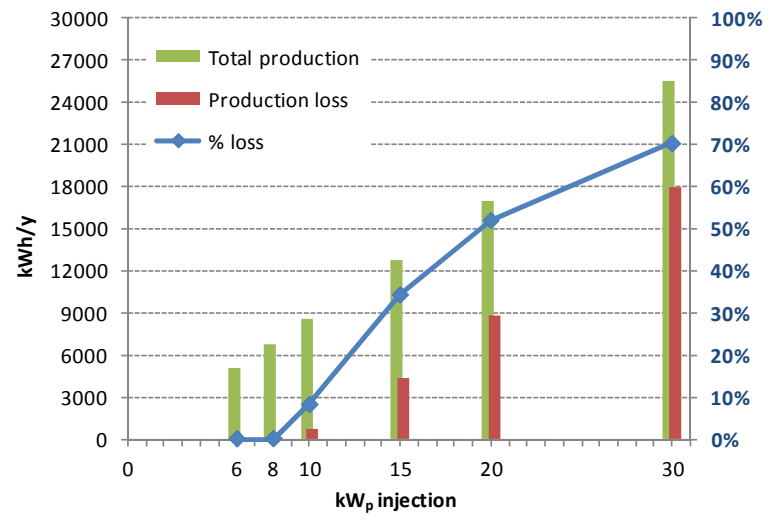

Fig. 8. Yearly production and loss due to overvoltage vs. PV peak power in case of single phase injection at the end of the feeder and all phases loaded by $12 \times 3 \mathrm{~kW}_{\mathrm{p}}$ profiles

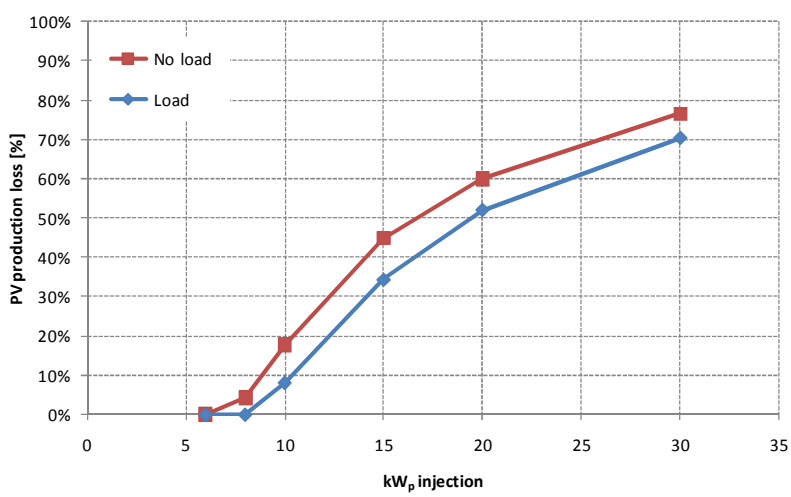

Fig. 9. Yearly production loss due to overvoltage vs. PV peak power in case of load and no load conditions
Table IV. - Yearly production and loss due to overvoltage vs. PV peak power in case of no load

\begin{tabular}{|r|c|c|c|c|c|c|l|}
\hline INSTALLED & 6 & 8 & 10 & 15 & 20 & 30 & $\mathrm{kWp}$ \\
\hline TOTAL & 5100 & 6800 & 8500 & 12750 & 17000 & 25500 & $\mathrm{kWh} / \mathrm{y}$ \\
\hline LOSS & 0 & 292,6 & 1512 & 5714 & 10202 & 19510 & $\mathrm{kWh} / \mathrm{y}$ \\
\hline$\%$ LOSS & 0 & 4,30 & 17,79 & 44,81 & 60,01 & 76,51 & $\%$ \\
\hline
\end{tabular}

\section{Further research}

The exponential growth of DG is creating the voltage problem as stated above. The same analysis will be performed for Small Wind Turbines. Further research will be done to minimize these problems, such as limiting the injectable current, with local storage or limiting the MPPT of the inverter, and the implementation of these algorithms in so called smart inverters. Results can also be implemented in economic calculations to determine more realistic payback times [8].

\section{Conclusions}

This paper gives a general approach for the determination of the maximum power acceptance in residential areas. Using the equivalent power injection approach, the available power injection capacity or the possible violation of voltage limits can be quickly estimated. Guidelines are proposed to calculate PV production losses due to overvoltage. This guideline can be used to choose the peak power of a PV installation. Simulations and calculations are performed for a Belgian residential area. However the methodology can be generally applied.

\section{References}

[1] M. Mes, G.M.A. Vanalme, J.M.A. Myrzik, M. Bongaerts, G.J.P. Verbong, W.L. Kling, "Implementation of Distributed Generation in the Dutch LV Network - SelfSupporting Residential Area", in Proc. UPEC 2008, 1-4 September 2008, Padova, Italy

[2] D.H. Popović, J.A. Greatbanks, M. Begović, A. Pregelj, "Placement of distributed generators and reclosers for distribution network security and reliability", International Journal of Electrical Power \& Energy Systems, vol. 27(56), pp. 398-408, 2005.

[3] Synergrid C10-11 Specific technical connection instructions for grid connected distributed generation, May 2009 (www.synergrid .be)

[4] EN50160, Voltage characteristics of electricity supplied by public distribution networks, 2007.

[5] Data obtained from the Flemish Regulation Entity for the Electricity and Gas Market (VREG)

[6] Standard sunlight radiation parameters obtained from KMI

[7] R. Dogniaux, M. Lemoine, R. Sneyers, "Année type moyenne pour le traitement de problèmes de captation d'énergie solaire", KMI, 1978

[8] B. Verhelst, J. Desmet, C. Debruyne, L. Vandevelde and H. Van Landeghem, "Technical and business economic study of photovoltaic systems”, accepted for ICREPQ 2010. 


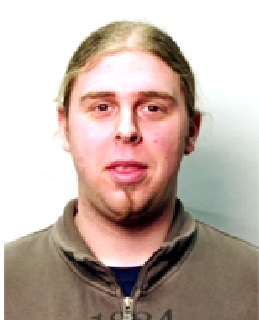

Colin Debruyne received the Master Industrial Engineering degree in Electrotechnical Engineering from the Technical University HoWest, Kortrijk, Belgium, in 2004. Since 2004 he has been a researcher at the Technical University HoWest, Kortrijk, mainly in the field of power quality and general electrotechnical engineering. Since '09 he is a Ph.D. student at the University of Ghent, Ghent, Belgium, where he is working on improving the magnetization of permanent magnet synchronous motors by supplying a non sinusoidal wave shape. His research interests include low voltage grid analysis, general power quality issues and electrical machines.

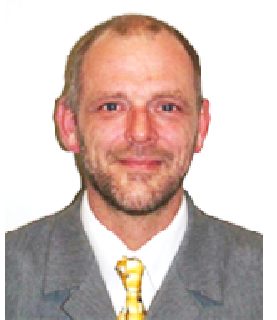

Jan J. M. Desmet received the Polytechnical Engineer degree from the polytechnic academy in Kortrijk, Belgium, in 1983, the M.Sc. degree in Electrical Engineering in 1993 from the V.U.Brussels, Belgium and in 2008 his Ph.D. degree at the K.U.Leuven, Belgium. Currently he is full professor at the Technical University Howest teaching power quality, renewables and industrial electric measurement techniques. His research interests include energy efficiency, renewable, power quality and their mutual interactions. He is also IASTED and IEEE member, member of SC77A (IEC) and TC210 (CENELEC).

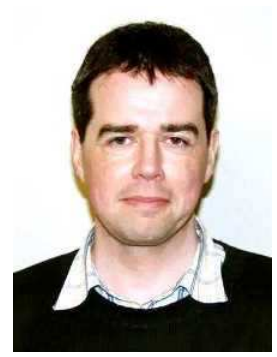

Johan Vanalme received the M.Sc. degree in Electronics Engineering from the University of Ghent, Ghent, Belgium, in 1990, and post-graduated in Business Administration at K.U.Leuven, Kortrijk, Belgium, in 1996. He was with Barco, Kuurne, Belgium, as Electronic Development Engineer, where he designed high end electronics and embedded software for the professional image projection market. Since 2006, he is a researcher at the Technical University Howest, Kortrijk, Belgium, and associate researcher at the University of Ghent, Engineering Faculty, Department of Electrical Energy, Systems and Automation, Laboratory of Electrical Energy, Ghent, Belgium. He worked on electric motor drive systems and is currently involved in distributed generation and power quality.

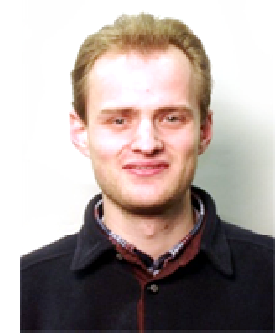

Bart Verhelst received his Master Industrial Engineering degree in Electrotechnical Engineering from the Technical University HoWest, Kortrijk, Belgium, in 2004, and received his Masters degree in Industrial Management from the University of Ghent, Ghent, Belgium, in 2009.

Since 2004 he is a full time researcher at the Technical University HoWest, Kortrijk, Belgium, mainly in the field of power quality, renewables and electrotechnical engineering. In 2009 he added economics to his field of research. $\mathrm{He}$ is member of the Institute of Industrial Engineering (IIE).

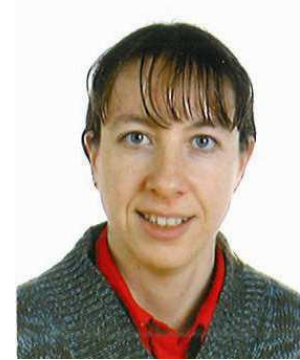

Greet Vanalme received the M.Sc. degree in Electronics Engineering in 1994 and the Ph.D. degree in Sciences in 2000 from the University of Ghent, Belgium. Since 2000, she is researcher at the Technical University HoWest, Kortrijk, Belgium. Since 2007, she is also part-time assistant professor at the Electrical Power Systems (EPS) group of the University of Technology Eindhoven, The Netherlands. Her research interests include power quality, distributed generation and energy efficiency.

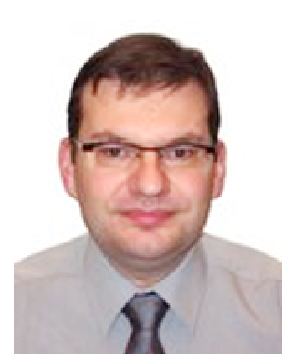

Lieven Vandevelde was born in Eeklo, Belgium in 1968. He graduated in electromechanical engineering at Ghent University in 1992 and is since then with the Electrical Energy Laboratory (EELAB). He received the Ph.D. degree from Ghent University in 1997.

Since 2004, he is professor in electrical power engineering. His research and teaching activities are in the field of electrical power systems, electrical machines and (computational) electromagnetics. 